\title{
Rates of mental disorder in people convicted
}

\section{of homicide}

National clinical survey ${ }^{\dagger}$

\author{
JENNY SHAW, ISABELLE M. HUNT, SANDR A FLYNN, JANET MEEHAN, \\ JO ROBINSON, HARRIET BICKLEY, REBECCA PARSONS, KERRY MCCANN, \\ JAMES BURNS, TIM AMOS, NAVNEET KAPUR and LOUIS APPLEBY
}

\section{Background Previous studies of people convicted of homicide have used different definitions of mental disorder.}

\begin{abstract}
Aims To estimate the rate of mental disorder in people convicted of homicide; to examine the relationship between definitions, verdict and outcome in court.
\end{abstract}

Method A national clinical survey of people convicted of homicide $(n=1594)$ in England and Wales (1996-1999). Rates of mental disorder were estimated based on: lifetime diagnosis, mental illness at the time of the offence, contact with psychiatric services, diminished responsibility verdict and hospital disposal.

Results Of the 1594, 545 (34\%) had a mental disorder: most had not attended psychiatric services; 85 (5\%) had schizophrenia (lifetime); 164 (10\%) had symptoms of mental illness at the time of the offence; 149 (9\%) received a diminished responsibility verdict and III (7\%) a hospital disposal - both were associated with severe mental illness and symptoms of psychosis.

Conclusions The findings suggest an association between schizophrenia and conviction for homicide. Most perpetrators with a history of mental disorder were not acutely ill or under mental healthcare at the time of the offence. Some perpetrators receive prison sentences despite having severe mental illness.

Declaration of interest L.A. is the National Director of Mental Health for England. Funding detailed in Acknowledgements.
There is widespread public fear that people with mental disorder pose a significant risk of interpersonal violence (Phelan \& Link, 1998) but studies have shown that the order of the association between violence and mental disorder is small (Swanson et al, 1990; Hodgins, 1992; Tiihonen et al, 1997; Arsenault et al, 2000; Brennan et al, 2000). Studies of mental disorder in people convicted of homicide have found rates between 8 and $70 \%$ (Wong \& Singer, 1973; Gudjonsson \& Petursson, 1986; Linqvist \& Allebeck, 1990; Taylor \& Gunn, 1999), varying with different definitions of mental disorder. This paper describes a national consecutive series of homicide convictions. The aims of the study were to estimate the rate of mental disorder among those convicted, according to clinical service and criminal justice definitions, and to examine the relationship between definitions and mental health 'disposal'. The study was carried out as part of the National Confidential Inquiry into Suicide and Homicide by People with Mental Illness (Appleby et al, 2001).

\section{METHOD}

As in the suicide inquiry, data collection had three stages: the collection of a comprehensive national sample of homicides; the retrieval of psychiatric reports on those convicted, irrespective of mental health history; the collection of clinical data on those known to have had contact with mental health services.

\section{Total homicide sample}

The names of those convicted of homicide (murder, manslaughter or infanticide) were notified to the Inquiry by the Home Office, which routinely collects this information in the Homicide Index. This data source provided demographic information on the

†See pp. 129-134 and 135-142, this issue. perpetrator and victims and details about the offence, sentencing and outcome in court.

\section{Psychiatric reports}

Psychiatric reports were requested from the courts of trial, the Prison Service, the Crown Prosecution Service and other sources. The following information was extracted from the reports: demographic characteristics; clinical history; mental state at time of offence; presence of alcohol/drug dependence and misuse; and the role these substances played in the offence. Records of previous offences were obtained from the Police National Computer.

\section{Collection of clinical data}

Identifying details on each homicide perpetrator were submitted to the main hospital and community trusts providing mental health services to people living in the perpetrator's district of residence. When trust records showed that contact with services had occurred at any time, the person became an 'inquiry case'. For each inquiry case, the consultant was sent a questionnaire which they were asked to complete after discussion with other members of the mental health team. The questionnaire consisted of sections covering demographic characteristics, clinical history, history of violence, aspects of care, details of final contact with services and respondents' views on prevention.

\section{Rates of mental disorder}

The presence of mental disorder was recorded using the following definitions:

(a) clinical history: lifetime diagnosis of mental disorder, based on information from psychiatric reports and questionnaires;

(b) recent symptoms: mental illness, i.e. typical symptoms of mood disorder or psychosis at the time of the offence, based on psychiatric reports;

(c) previous care: contact with mental health services, based on reports and questionnaire data;

(d) verdict: manslaughter on the grounds of diminished responsibility, based on the homicide index data;

(e) outcome: commitment to psychiatric hospital, based on the homicide index data. 
We examined the relationship between the above groups, and between the clinical definitions and verdict and outcome.

\section{Diagnosis of affective disorder and schizophrenia}

For the purposes of this paper, we identified a lifetime history of affective disorder or schizophrenia only if this was diagnosed either by the psychiatrist preparing the court report or by the psychiatrist completing the questionnaire (for those in contact with mental health services). We concluded that a person had depression at the time of the offence only if they fulfilled ICD-10 (World Health Organization, 1992) criteria for depression, judged by an experienced psychiatrist attached to the research team (J.M.). Diagnoses were cross-checked by another psychiatrist attached to the team (J.S.) and there was $100 \%$ agreement. In a small number of cases of schizophrenia, there was a discrepancy between the diagnosis given in the psychiatric report and that assigned by services. In these cases, the psychiatric reports and questionnaires were individually examined by one of the authors (J.M.) using a standardised procedure to make the diagnosis based on: duration of history, degree of contact with services, timing of the most recent assessment or contact, identification of symptoms and strength of agreement between report writers (in cases with more than one report prepared for court). Some of the diagnostic discrepancies were explained by services having had contact with the person many years earlier when features of schizophrenia were not present. In other cases, the information contained within the psychiatric report was limited and services had a better knowledge of the perpetrator's history over a long period of time.

\section{Statistical analysis}

The main findings are presented as proportions with $95 \%$ confidence intervals. If an item of information was not known for a case, the case was removed from the analysis of that item. The denominator in all estimates is therefore the number of valid cases for each time. Subgroup analysis was carried out using $\chi^{2}$-tests with statistical significance set at $P<0.05$. Where comparisons are given for verdicts and the disposal received, a diminished responsibility verdict is compared with verdicts for murder, other manslaughter, infanticide, unfit to plead or not guilty by reason of insanity. A hospital disposal is compared with imprisonment, probation orders and suspended sentences.

\section{RESULTS}

\section{Homicide convictions}

The Inquiry was notified of 1579 homicide convictions in England and Wales during the 3 years from April 1996. In an additional 15 cases notified to the Inquiry the defendant was found unfit to plead or not guilty by reason of insanity, bringing the total number of homicides to 1594 . We obtained one or more reports prepared for the court in 1168 cases $(73 \% ; 1155$ convicted and 13 unfit to plead or not guilty by reason of insanity).

Of the perpetrators, 1434 (90\%) were male; the median age was 27 years (range 10-77); 515/1130 (46\%) male victims were aged 18-35 years; of the 1432 cases in which relationship with the victim was known, 511 perpetrators (36\%) killed a family member or a current or former spouse/partner, over a third $(563,39 \%)$ killed an acquaintance and a quarter $(358,25 \%)$ killed a stranger. The most common method of killing was stabbing $(594 / 1594,37 \%)$.

\section{Rates of mental disorder}

The rate of mental disorder according to each definition is shown in Table 1. Figure
1 shows the overlap between clinical definitions. Table 2 shows how many cases according to each definition led to a diminished responsibility verdict or a hospital order.

\section{Lifetime diagnosis of mental disorder}

Mental disorder by this definition was found in almost half of those with psychiatric reports and around a third of all cases. In most the disorder was not a severe mental illness, the most common diagnoses being personality disorder, alcohol dependence and drug dependence. However, there were 85 perpetrators with a lifetime diagnosis of schizophrenia, an average of 28 cases per year (over the 3-year study). Less than half of those with a lifetime history had ever had contact with mental health services, and a third had an abnormal mental state at the time of the offence (Fig. 1).

Verdict and disposal varied with diagnosis (Table 2). Most of those with schizophrenia received a diminished responsibility verdict and/or a hospital disposal. Those who received a diminished responsibility verdict were more likely to be female (20 v. $3 \%, \chi^{2}=4.8, P=0.048$ ), less likely to have previous convictions for violence (22 $\left.v .48 \%, \chi^{2}=6.2, P=0.013\right)$ and more likely

Table I Rates of mental disorder in people convicted of homicide

\begin{tabular}{|c|c|c|c|}
\hline & $n$ & $\begin{array}{l}\% \text { of all homicides } \\
\qquad \begin{array}{c}(95 \% \mathrm{Cl}) \\
(n=1594)\end{array}\end{array}$ & $\begin{array}{l}\% \text { of all homicides } \\
\text { with psychiatric } \\
\text { reports }(95 \% \mathrm{Cl}) \\
(n=1168)\end{array}$ \\
\hline Mental disorder (lifetime)' & 545 & $34(32-37)$ & $45(42-48)$ \\
\hline Schizophrenia ${ }^{2}$ & 85 & $5 \quad(4-6)$ & $7 \quad(6-9)$ \\
\hline Affective disorder & 118 & $7 \quad(6-9)$ & $10(8-12)$ \\
\hline Personality disorder & 143 & $9(8-10)$ & II (10-13) \\
\hline Alcohol dependence & 117 & $7 \quad(6-9)$ & $10(8-12)$ \\
\hline Drug dependence & 95 & $6 \quad(5-7)$ & $8(7-10)$ \\
\hline Abnormal state at time of offence ${ }^{3}$ & 164 & $10(9-12)$ & $14(12-16)$ \\
\hline Psychosis at time of offence & 76 & $5 \quad(4-6)$ & $6 \quad(5-9)$ \\
\hline Depression at time of offence & 101 & $6 \quad(5-8)$ & $9(7-10)$ \\
\hline \multicolumn{4}{|l|}{ Contact with mental health services } \\
\hline Lifetime & 282 & $18(16-20)$ & $22(19-24)$ \\
\hline Within 12 months of the offence & 145 & $9(8-I I)$ & II (9-13) \\
\hline $\begin{array}{l}\text { Convicted of Section } 2 \text { manslaughter } \\
\text { (diminished responsibility) }\end{array}$ & 149 & $9(8-I I)$ & $13(|1-| 4)$ \\
\hline Hospital order & III & $(6-8)$ & 9 (8-II) \\
\hline
\end{tabular}

I. Some perpetrators had dual diagnoses.

2. Number of perpetrators with schizophrenia found unfit to plead $=3$; not guilty by reason of insanity=4.

3. Some perpetrators had more than one symptom. 


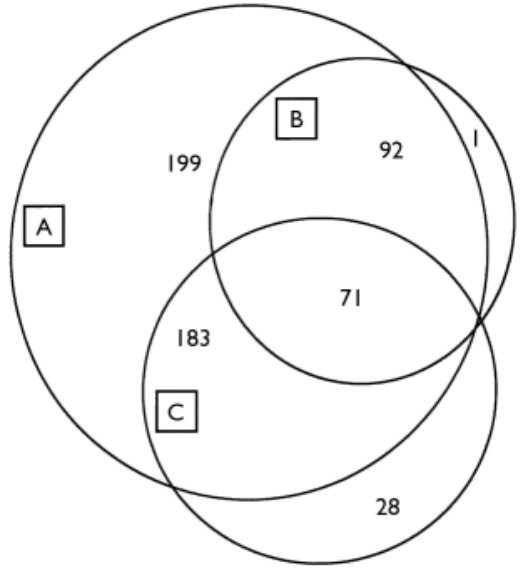

Fig. I Overlap between clinical definitions of mental disorder in people convicted of homicide. A, mental disorder (lifetime) $n=545 ; B$, abnormal mental state at the time of the homicide $n=164$;

C, contact with services (lifetime) $\mathbf{n}=\mathbf{2 8 2}$.

to have had hallucinations at the time of the offence (39 v. 10\%, $\left.\chi^{2}=5.6, P=0.021\right)$. Those receiving a hospital order were also less likely to have previous convictions for violence $\left(25 v .63 \%, \chi^{2}=8.6, P=0.003\right)$.

Among those with a lifetime history of affective disorder, a diminished responsibility verdict was associated with having depression (93 v. 61\%, $\chi^{2}=13.3$, $P<0.001)$ or delusions $(26$ v. $1 \%$,

Table 2 Verdict of Section 2 manslaughter (diminished responsibility) and hospital order disposal according to clinical definition

\begin{tabular}{lrcr}
\hline & $n$ & $\begin{array}{c}\text { Manslaughter } \\
\text { (diminished responsibility) } \\
n(\%)\end{array}$ & $\begin{array}{c}\text { Hospital order } \\
n(\%)\end{array}$ \\
\hline Mental disorder (lifetime) & & $137(25)$ & $108(20)$ \\
Schizophrenia & & $54(64)$ & $69(81)$ \\
Affective disorder & 545 & $41(35)$ & $21(18)$ \\
Personality disorder & 85 & $26(18)$ & $8(6)$ \\
Alcohol dependence & 118 & $17(15)$ & $5(4)$ \\
$\quad$ Drug dependence & 143 & $10(11)$ & $3(3)$ \\
Abnormal state at time of offence ${ }^{3}$ & 117 & $94(57)$ & $78(48)$ \\
$\quad$ Psychosis at time of offence & 95 & $54(71)$ & $61(80)$ \\
$\quad$ Depression at time of offence & 164 & $50(50)$ & $27(27)$ \\
Contact with mental health services & 10 & & $69(24)$ \\
Lifetime & 282 & $72(26)$ & $42(29)$ \\
Within I2 months of the offence & 145 & $44(30)$ & $83(56)$ \\
Convicted of Section 2 manslaughter & 149 & - & \\
(diminished responsibility) & & &
\end{tabular}

I. Some perpetrators had dual diagnoses.

2. Number of perpetrators with schizophrenia found unfit to plead $=3$; not guilty by reason of insanity $=4$.

3. Some perpetrators had more than one symptom. $\left.\chi^{2}=16.4, P<0.001\right)$ at the time of the offence and with killing a family member or spouse ( $88 v .68 \%, \chi^{2}=5.8, P=0.016$ ). Hospital disposal was more likely in those who were psychotic at the time of the killing (52 v. $\left.2 \%, \chi^{2}=44.6, P<0.001\right)$ and less likely if there was a history of alcohol misuse $\left(11 v .39 \%, \chi^{2}=5.6, P=0.018\right)$.

\section{Mental illness at the time of the offence}

Of the 164 people with symptoms of mental illness at the time of the offence, $76(46 \%)$ had symptoms of psychosis (delusions and/or hallucinations) and 101 $(62 \%)$ had symptoms of depression (Table 2). The majority of those with psychotic symptoms had been in contact with mental health services at some time, although this was often over a year previously; most of those with depressive symptoms had never been in contact with services.

The majority of those with psychotic symptoms received a diminished responsibility verdict and a hospital order. Those who received a diminished responsibility verdict were less likely to have a history of alcohol misuse (25 v. 58\%, $\chi^{2}=7.0$, $P=0.008$ ). Those who received a hospital order were less likely to have co-morbid drug dependence ( 3 v. 40\%, $\chi^{2}=16.9$, $P=0.001)$ and alcohol was less likely to

have contributed to the offence (10 $v$. $\left.33 \%, \chi^{2}=5.2, P=0.02\right)$. In those with symptoms of depression at the time of the offence, a diminished responsibility verdict was associated with being psychotic (20 v . $\left.6 \%, \chi^{2}=4.5, P=0.04\right)$ or having delusions (21 v. $4 \%, \chi^{2}=6.3, P=0.02$ ) at that time.

\section{Contact with mental health services (Inquiry cases)}

The main diagnoses in the 282 people with any previous contact with mental health services were schizophrenia $(60,24 \%)$, personality disorder $(45,18 \%)$, depressive disorder $(39,16 \%)$, alcohol dependence $(25,10 \%)$ and drug dependence $(25,10 \%)$.

In those with any previous contact with services a diminished responsibility verdict was associated with being female (28v. $\left.15 \%, \chi^{2}=6.1, P=0.013\right)$, a diagnosis of schizophrenia $\left(56 \quad v . \quad 10 \%, \chi^{2}=65.6\right.$, $P<0.001)$ and killing a family member or spouse ( 58 v. $39 \%, \chi^{2}=8.1, P=0.004$ ). Hospital disposal was associated with service contact in the year before the offence (67 v. 46\%, $\chi^{2}=8.5, P=0.004$ ), a diagnosis of schizophrenia (74 v. 5\%, $\chi^{2}=147.3, P<0.001$ ), psychotic symptoms at the time of the homicide (58 v. 3\%, $\left.\chi^{2}=112.2, \quad P<0.001\right)$, being unmarried (80 v. 64\%, $\chi^{2}=5.7, P=0.017$ ), belonging to a minority ethnic group (23 v. 3\%, $\left.\chi^{2}=27.6, P<0.001\right)$ and killing a family member or spouse $\left(57 v .40 \%, \chi^{2}=5.8\right.$, $P=0.016$ ).

\section{Manslaughter on the grounds of diminished responsibility}

Among the 149 people receiving a verdict of manslaughter on the grounds of diminished responsibility the outcome was a hospital order for $83(56 \%)$. In the remaining cases, the disposal was prison for 55 $(37 \%)$, probation order for $8(5 \%)$, suspended sentence for $2(1 \%)$ and Guardianship under the Mental Health Act 1983 for $1(0.7 \%)$.

Hospital disposal was associated with previous contact with mental health services (63 v. $30 \%, \chi^{2}=15.4, P=0.001$ ), a lifetime diagnosis of mental disorder (98 v. $85 \%, \chi^{2}=8.1, P=0.006$ ) or symptoms of mental illness at the time of the offence (79 $v 44 \%, \chi^{2}=19.7, P=0.001$ ). Hospital disposal was less likely in those who had a history of alcohol misuse $(29 v .52 \%$, $\left.\chi^{2}=7.9, \quad P=0.005\right)$ or previous violent convictions (18 v. 35\%, $\chi^{2}=5.5, P=0.02$ ) and when alcohol had contributed to the offence (17 v. 41\%, $\left.\chi^{2}=9.9, P=0.002\right)$. 
Of the 23 perpetrators who had symptoms of mental illness at the time of the offence, and who were convicted of Section 2 manslaughter yet sent to prison, 20 $(87 \%)$ were depressed at the time of the killing; 17 (74\%) had a lifetime diagnosis of affective disorder, 3 had a diagnosis of schizophrenia, 2 had primary alcohol dependence and 1 had personality disorder.

\section{DISCUSSION}

Our findings show that the rate of mental disorder in people convicted of homicide varies widely according to the definition used. The broadest definition, a lifetime history of any disorder, gives a rate of at least one-third, although this may not be higher than in the general population, in whom a similar rate has been reported when diagnosis has been based on lifetime history (Meltzer, 1995). However, our figure of $5 \%$ of perpetrators with schizophrenia is higher than any published population prevalence figure and suggests an association between schizophrenia and conviction for homicide.

Second, we have also found limited overlap between definitions, including between clinical definitions. Although most perpetrators with an abnormal mental state at the time of the killing or with a history of service contact also received a lifetime diagnosis, the converse was not true. In other words, most perpetrators with a history of mental disorder were not acutely ill when they killed and most had never received mental healthcare, suggesting that services could not have prevented their offences.

Third, it is clear that mental disorder by any definition does not necessarily lead to a mental health disposal in court. In general, both a verdict of diminished responsibility and a hospital order are related to severe mental illness rather than alcohol or drug dependence or personality disorder and to abnormalities of mental state, especially psychosis, at the time of the killing. This is justifiable in a system which aims to identify those whose illnesses are most serious and most treatable. However, a small number of those with acute and severe mental illness are sent to prison, even after a verdict of diminished responsibility.

\section{Methodological issues}

The sample sizes in this study are larger than in most previous clinical studies of homicide. However, several

\section{CLINICAL IMPLICATIONS}

- Rates of mental disorder in those convicted of homicide vary according to the definition used; a third had a lifetime history of mental disorder but $10 \%$ had symptoms of mental illness at the time of the offence.

Most of those with a lifetime history of mental disorder were not in contact with mental health services; the potential for prevention was therefore limited.

Hospital orders were associated with severe mental illness and psychotic symptoms.

\section{LIMITATIONS}

Psychiatric reports with clinical data were not available for a quarter of cases.

Diagnoses were based on clinicians' judgements and were not standardised.

Clinicians providing information may have been biased by their awareness of outcome.

ENNY SHAW, MBBS, MRCPsych, PhD, ISABELLE M. HUNT, BSc, SANDRA FLYNN, BA, JANET MEEHAN, MBChB, MRCPsych, JO ROBINSON, MSc, HARRIET BICKLEY, BA, REBECCA PARSONS, BA, KERRY McCANN, BSc, JAMES BURNS, BA, TIM AMOS, MA, MSc, MBBS, MRCPsych, DPMSA, NAVNEET KAPUR, MBChB, MMedSc, MRCPsych, MD, LOUIS APPLEBY, MD, FRCP, FRCPsych, Centre for Suicide Prevention, University of Manchester, Manchester, UK

Correspondence: Professor Louis Appleby, Centre for Suicide Prevention, University of Manchester Williamson Building, Oxford Road, Manchester MI3 9PL, UK. E-mail: Louis.appleby@manchester.ac.uk

(First received 4 June 2004, final revision 8 February 2005, accepted 16 March 2005)

methodological limitations must be highlighted. Psychiatric reports were available for only $73 \%$ of the sample and are more likely to have been requested for those with mental disorder. For this reason, Table 1 presents proportions of all cases and all those with reports. Second, the information in reports and questionnaires was based on clinical judgements rather than standardised assessments. However, the reliability and validity of Inquiry questionnaire data have been shown to be good (Appleby et al, 1999).

\section{Clinical and research implications}

The contribution of mental disorder to violent actions and its handling by the criminal justice system are complex and sensitive issues. Our findings suggest the need for detailed studies of individual disorders and of decision-making by psychiatrists and courts. Findings such as these also need to be kept under review because, as evidence on the aetiology and treatment of personality disorder and substance misuse is collected, perceptions of responsibility and 'treatability' in these conditions may change. The way the courts deal with acute or severe mental illness also needs to be examined regularly - despite improvements to prison mental healthcare (National Institute for Mental Health in England, 2005), people with such illnesses cannot receive the care they need if they are imprisoned.

\section{ACKNOWLEDGEMENTS}

This study was carried out as part of the National Confidential Inquiry into Suicide and Homicide by People with Mental Illness (Appleby et al, 1999). The Inquiry was funded by the National Institute for Clinical Excellence and is currently funded by the National Patient Safety Agency. We acknowledge the help of district directors of public health, health authority, trust and crown court contacts, and that of consultant psychiatrists in completing the questionnaires.

\section{REFERENCES}

Appleby, L., Shaw, J., Amos, T., et al (1999) Safer Services. Report of the National Confidential Inquiry into Suicide and Homicide by People with Mental Illness. London: Department of Health. 
Appleby, L., Shaw, J., Sherratt, J., et al (200I) Safety First: Five-Year Report of the National Confidential Inquiry into Suicide and Homicide by People with Mental Illness. London: Department of Health

Arsenault, L., Caspi, A., Moffitt, T. E., et al (2000) Mental disorders and violence in a total birth cohort. Archives of General Psychiatry, 57, 979-986.

Brennan, P. A., Grekin, E. R. \& Vanman, E. J. (2000) Major mental disorders and crime in the community. In Violence Among the Mentally III (ed. S. Hodgins).

Dordrecht: Kluwer Academic Publishers.

Gudjonsson, G. H. \& Petursson, H. (1986) Changing characteristics of homicide in Iceland. Medical Science and Law, 26, 299-303.

Hodgins, S. (1992) Mental disorder, intellectual deficiency and crime. Evidence from a birth cohort. Archives of General Psychiatry, 49, 476-483.
Linqvist, P. \& Allebeck, P. (1990) Schizophrenia and crime. A longitudinal follow-up of 644 schizophrenics in Stockholm. British Journal of Psychiatry, I57, 345-350.

Meltzer, H. (1995) OPCS Survey of Psychiatric Morbidity in Great Britain. London: Office of Population Censuses and Surveys.

National Institute for Mental Health in England (2005) Offender Mental Health Care Pathway. London: Department of Health

Phelan, J. C. \& Link, B. G. (1998) The growing belief that people with mental illnesses are violent: the role of the dangerousness criterion for civil commitment. Socia Psychiatry and Psychiatric Epidemiology, 33, S7-SI2.

Swanson, J. W., Holzer, C. F., Ganju, V. K., et al (1990)

Violence and psychiatric disorder in the community

Evidence from the Epidemiologic Catchment Area

Surveys. Hospital and Community Psychiatry, 4I, 76I-770.
Taylor, P. J. \& Gunn, J. (1999) Homicides by people with mental illness: myth and reality. British journal of Psychiatry, 174, 9-14.

Tiihonen, J., Isohanni, M., Raesaenen, P., et al (1997) Specific major mental disorders and criminality. A 26 year prospective study of the 1996 Northern Finland Birth Cohort. American Journal of Psychiatry, I54, 840-845.

Wong, M. \& Singer, K. (1973) Abnormal homicide in Hong Kong. British Journal of Psychiatry, I23, 295-298.

World Health Organization (1992) The ICD-10 Classification of Mental and Behavioural Disorders. Geneva: WHO. 